\title{
Laparoscopic Heller Myotomy and Dor Fundoplication for the Treatment of Esophageal Achalasia After Sleeve Gastrectomy-a Video Vignette
}

\author{
Alberto Aiolfi ${ }^{1}$ (D) Diego Foschi ${ }^{2}$ - Marco Antonio Zappa ${ }^{3} \cdot$ Alessandra Dell'Era $^{2} \cdot$ Emilia Bareggi $^{2} \cdot$ Emanuele Rausa $^{4}$. \\ Giancarlo Micheletto $^{5}$. Davide Bona ${ }^{1}$
}

Received: 3 October 2020 / Revised: 5 November 2020 / Accepted: 10 November 2020 / Published online: 24 November 2020

(C) The Author(s) 2020

\begin{abstract}
Purpose Esophageal dysmotility and disorders of the lower esophageal sphincter are well documented in morbidly obese patients. Esophageal achalasia has been reported in up to $1 \%$ of obese patients but the development of such esophageal motility disorder after laparoscopic sleeve gastrectomy (LSG) is extremely rare. The purpose of this video was to demonstrate the management of a type II esophageal achalasia diagnosed in a 46-year-old female patient 4-year after LSG.

Materials and Methods An intraoperative video has been anonymized and edited to demonstrate the feasibility of laparoscopic Heller myotomy and anterior Dor fundoplication on the mentioned patient.

Results The operation started with the section of the perigastric adhesions. Proceeding in a clockwise direction, the esophagogastric junction, the anterior esophageal wall, and the His angle were freed. A residual slightly dilated fundus was found and isolated. After mobilization of the distal esophagus and identification of the anterior vagus nerve, a "hockey stick" myotomy was carried out for $6 \mathrm{~cm}$ on the esophagus and for $2 \mathrm{~cm}$ on the gastric side. An anterior Dor fundoplication was fashioned using the residual gastric fundus.

Conclusion Esophageal achalasia in patients that previously underwent LSG is exceptional but should always be suspected in case of pathognomonic symptoms onset. In tertiary referral centers, laparoscopic Heller myotomy and, if technically feasible, an anterior Dor fundoplication seem safe and effective to relieve gastroesophageal outflow obstruction and prevent gastroesophageal reflux.
\end{abstract}

Keywords Laparoscopic sleeve Gastrectomy $\cdot$ Heller myotomy $\cdot$ Dor fundoplication $\cdot$ Video vignette

\author{
Alberto Aiolfi \\ alberto.aiolfi86@gmail.com \\ Diego Foschi \\ diego.foschi@unimi.it \\ Marco Antonio Zappa \\ marcoantoniozappa@libero.it \\ Alessandra Dell'Era \\ Alessandra.DellEra@unimi.it \\ Emilia Bareggi \\ bareggi.emilia@asst-fbf-sacco.it \\ Emanuele Rausa \\ emarausa@yahoo.it \\ Giancarlo Micheletto \\ giancarlo.micheletto@unimi.it
}

Davide Bona

davide.bona@unimi.it

1 Department of Biomedical Science for Health, Division of General Surgery Istitituto Clinico Sant'Ambrogio, University of Milan, Via Luigi Giuseppe Faravelli, 16, 20149 Milan, Italy

2 Department of Biomedical and Clinical Sciences "Luigi Sacco", L. Sacco Hospital, Università degli Studi of Milan, 20157 Milan, Italy

3 ASST Fatebenefratelli Sacco, UOC di Chirurgia Generale, Milan, Italy

4 General Surgery I, Papa Giovanni XXIII Hospital, Bergamo, Italy

5 Department of Pathophysiology and Transplantation, INCO and Department of General Surgery, Istituto Clinico Sant'Ambrogio, University of Milan, Milan, Italy 


\section{Introduction}

Achalasia has been reported in up to $1 \%$ of morbidly obese patients [1]. The onset and diagnosis of esophageal achalasia arising after bariatric surgery is extremely rare $[2,3]$. While the onset of this motility disorder after Roux-en-Y Gastric Bypass (RYGB) seems more common, only four cases of esophageal achalasia after LSG have been reported in the literature [4]. The management of such patients is challenging; however, it is likely that because the increasing number of morbidly obese patients and concomitant increase in weightloss procedures (especially LSG), the number of these patients will growth in the future.

\section{Purpose}

The purpose of this video was to demonstrate the management of esophageal achalasia in a 46-year-old female patient that underwent LSG for morbid obesity (weight $137 \mathrm{~kg}$; BMI $39.8 \mathrm{~kg} / \mathrm{m} 2$ ). The patient was referred to our institution 4 years after the index procedure (weight $46 \mathrm{~kg}$; BMI $20.1 \mathrm{~kg} / \mathrm{m}^{2}$ ) for worsening solid food and paradoxical dysphagia (Eckardt score 2-2-1-2) with anomalous ongoing weight loss. The high resolution manometry was suggestive for a type II achalasia with esophageal panpressurization.

\section{Methods}

An intraoperative video has been edited to demonstrate the feasibility of a patient-tailored laparoscopic Heller myotomy and Dor fundoplication. Written informed consent was obtained from the patient.

\section{Results}

The operation started with the section of the perigastric adhesions. Proceeding in a clockwise direction, the esophagogastric junction, the anterior esophageal wall, and the His angle were freed. A residual slightly dilated fundus was noticed and freed from posterior adhesions. The distal esophagus was mobilized and the anterior vagus nerve identified. A "hockey stick" myotomy was carried out for $6 \mathrm{~cm}$ on the esophagus and for $2 \mathrm{~cm}$ on the gastric side to include the oblique fibers (Helvetius collar) (Fig. 1). Intraoperative endoscopy with careful insufflation was negative for air leak. An anterior Dor fundoplication was fashioned by using the residual fundus that was secured to the left and right edge of the myotomy with interrupted non-absorbable sutures (Prolene

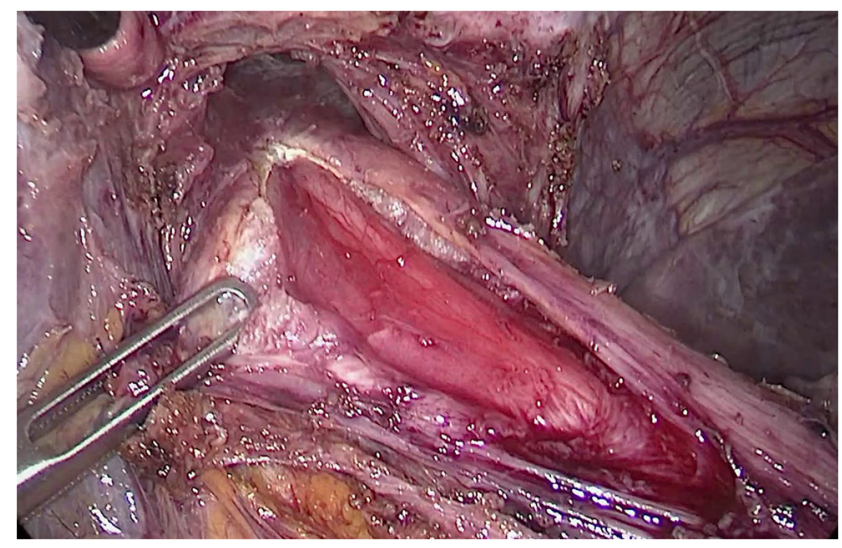

Fig. 1 The myotomy is performed by sectioning the circular and longitudinal muscular layers $6 \mathrm{~cm}$ on the esophagus. The myotomy is then extended $2 \mathrm{~cm}$ distally below the esophagogastric junction. The underlying mucosa is exposed

(®-Ethicon, Johnson \& Johnson, NJ, USA). The operative time was $85 \mathrm{~min}$. The postoperative course was uneventful and the patient was discharged on postoperative day 2. At 12-month follow-up, the patient was asymptomatic on a single-dose proton pump inhibitor and the 24-h pH-impedance test showed no evidence of pathologic reflux.

\section{Discussion}

The issue of whether an antireflux procedure should be added to the Heller myotomy has long been controversial. A 2004 randomized clinical trial showed the superiority of the myotomy plus Dor fundoplication versus myotomy alone with a significantly reduced postoperative pathologic reflux and esophageal acid exposure [5]. In accordance with these findings, fundoplication should be recommended after myotomy. None of the preoperative exams described the presence of a slightly dilated fundus and the decision to perform a Dor fundoplication was intraoperative and patient-tailored. The residual fundus allowed the fashioning of an anterior tension-free fundoplication with respect to valve geometry and lack of esophageal twisting. Furthermore, because of rapid and ongoing achalasiarelated weight loss, the conversion to a RYGB to prevent gastroesophageal reflux would have further worsened this condition.

The reported rate of mucosal perforation during Heller myotomy is up to $5 \%$ and dependent on surgeon's expertise [6]. We recommend endoscopic evaluation or air leak test via nasogastric tube as appropriate to check the integrity of the myotomy during the learning curve. In our referral center, endoscopy is used at surgeon discretion in challenging cases or after stitch repair for mucosal perforation. 


\section{Conclusion}

Esophageal achalasia after LSG is exceptional but should always be suspected in case of pathognomonic symptoms onset. In tertiary referral centers, a patient-tailored laparoscopic Heller myotomy and, if technically feasible, Dor fundoplication seem safe and effective to relieve symptoms and prevent gastroesophageal reflux.

Supplementary Information The online version contains supplementary material available at https://doi.org/10.1007/s11695-020-05114-x.

Funding Open access funding provided by Università degli Studi di Milano within the CRUI-CARE Agreement.

\section{Compliance with Ethical Standards}

Conflict of Interest All the authors declare no conflict of interest.

Human and Animal Rights All procedures performed in studies involving human participants were in accordance with the ethical standards of the institutional and/or national research committee and with the 1964 Helsinki Declaration and its later amendments or comparable ethical standards. This article does not contain any study with animals performed by any of the authors.

Informed Consent Written informed consent was obtained from the individual participant included in this video.

Open Access This article is licensed under a Creative Commons Attribution 4.0 International License, which permits use, sharing, adaptation, distribution and reproduction in any medium or format, as long as you give appropriate credit to the original author(s) and the source, provide a link to the Creative Commons licence, and indicate if changes were made. The images or other third party material in this article are included in the article's Creative Commons licence, unless indicated otherwise in a credit line to the material. If material is not included in the article's Creative Commons licence and your intended use is not permitted by statutory regulation or exceeds the permitted use, you will need to obtain permission directly from the copyright holder. To view a copy of this licence, visit http://creativecommons.org/licenses/by/4.0/.

\section{References}

1. Hampel H, Abraham NS, El-Serag HB. Meta-analysis: obesity and the risk for gastroesophageal reflux disease and its complications. Ann Intern Med. 2005;143(3):199-211.

2. Aiolfi A, Tornese S, Bonitta G, et al. Management of esophageal achalasia after Roux-en-Y gastric bypass: narrative review of the literature. Obes Surg. 2019;29(5):1632-7.

3. Boules M, Corcelles R, Zelisko A, et al. Achalasia after bariatric surgery. J Laparoendosc Adv Surg Tech A. 2016;26(6):428-32.

4. Oh HB, Tang SW, Shabbir A. Laparoscopic Heller's cardiomyotomy and Roux-en-Y gastric bypass for missed achalasia diagnosed after laparoscopic sleeve gastrectomy. Surg Obes Relat Dis. 2014;10(5):1002-4.

5. Richards WO, Torquati A, Holzman MD, et al. Heller myotomy versus Heller myotomy with Dor fundoplication for achalasia: a prospective randomized double-blind clinical trial. Ann Surg. 2004;240(3):405-12.

6. Boeckxstaens GE, Zaninotto G, Richter JE. Achalasia. Lancet. 2014;383(9911):83-93. https://doi.org/10.1016/S0140-6736(13) 60651-0.

Publisher's Note Springer Nature remains neutral with regard to jurisdictional claims in published maps and institutional affiliations. 